\title{
Experimental Investigation of Propfan Aeroelastic Response in Off-Axis Flow With Mistuning
}

(NASA-TH-1C1320) EXPEBIUEATAI INVESTIGATION N $88-28344$

CF PECPEAN AEFCEIESIIC BESECASE IA CFF-AXIS

FICW BITH UISTLNIG (NASA) ZS CSCI $20 \mathrm{~K}$

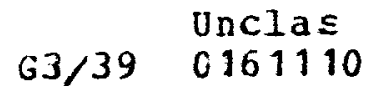

Oral Mehmed

Lewis Research Center

Cleveland, Ohio

and

Durbha V. Murthy

University of Toledo

Toledo, Ohio

Prepared for the

24th Joint Propulsion Conference

cosponsored by the AIAA, ASME, SAE, and ASEE

Boston, Massachusetts, July 11-13, 1988 


\title{
EXPERIMENTAL INVESTIGATION OF PROPFAN AEROELASTIC RESPONSE
}

\section{IN OFF-AXIS FLOW WITH MISTUNING}

\author{
Oral Mehmed* \\ National Aeronautics and Space Administration \\ Lewis Research Center \\ Cleveland, Ohio 44135 \\ and \\ Durbha V. Murthy** \\ University of Toledo \\ Toledo, Ohio 43606
}

\begin{abstract}
Measured vibratory strain amplitudes resulting from off-axis flow are compared for the blades of two, eight-bladed, $0.62 \mathrm{~m}(2 \mathrm{ft})$ diameter propfan model rotors with mistuning. One rotor had inherent mistuning. The other was intentionally mistuned by replacing every other blade of the first rotor with a blade of same geometry but different frequencies and mode shapes. The data shows that the intentional mistuning had a beneficial effect on the aeroelastic response of the propfan blades for a wide range of off-axis flow angles, blade. pitch angles, and rotational speeds. The data also illustrate that large and intuitively unpredictable variations in the aeroelastic response of propfan blades can occur because of inherent mistuning. Statistical trends of blade strain amplitudes are compared for both the rotors in terms of the ratio of the maximum to the mean and the coefficient of variation.
\end{abstract}

\section{INTRODUCTION}

Propfan, or advanced turboprop propulsion offers very high fuel efficiency at cruise speeds up to Mach 0.85 . However, to be fuel efficient at high flight speeds propfans have different geometric, structural and aerodynamic characteristics than conventional propellers. Typically, propfans have eight or more thin, flexible, twisted blades with large sweep and low aspect ratio. Because of these unique characteristics, the aeroelastic design technology used for conventional propellers is inadequate. To develop the required technology and establish a data base for designing propfans, Lewis Research Center has been conducting extensive research that includes both experimental and analytical aeroelasticity. As part of this research, wind tunnel experiments have been conducted with propfan models.

Because of manufacturing limitations, small property differences between the blades (mistuning) are inherent in all propfan rotors. However, propfan blades have been assumed to be of identical properties (tuned) in aeroelastic analyses performed (refs. 1 to 4). Analytical and experimental flutter results for a propfan rotor with intentionally mistuned blades were presented in references 5 and 6 . The present paper documents experimental work on aeroelastic

\footnotetext{
* Research Engineer; Member AIAA, ASME.

* NASA Resident Research Associate.
} 
response, due to off-axis flow, with mistuned propfan blades. Related analytical work and correlation between theory and experiment are presented in reference 7 .

Previous research (refs. 8 to 10) on turbomachinery bladed disks have shown that mistuning can have a significant effect on flutter and forced response. It is known that mistuning generally has a beneficial effect on the flutter characteristics of rotating blades. However, the effect of mistuning on forced response may be beneficial or adverse, depending on the system characteristics. These characteristics include: the amount and type of mistuning, the degree of structural and aerodynamic coupling between the blades, and the frequency and interblade phase angle of the excitation. As a result of this previous research, mistuning also was expected to be a factor affecting the aeroelastic forced response of propfan blades. This experiment was conducted to investigate the effects of frequency and mode shape mistuning on the aeroelastic forced response of two propfan rotors.

A major consideration in propfan blade design is aeroelastic forced response resulting from off-axis or angled flow into the rotor. It is common for propellers to have off-axis flow during take-off, climb and landing, when the propeller thrust.axis is inclined to the flow. Other sources of off-axis flow are airframe induced flow field distortions, wing upwash, and gusts. offaxis flow can cause large blade vibratory stresses and can lead to blade fatique failure. The vibration occurs because the off-axis flow causes the local angle of attack and the resultant velocity, at each blade section, to vary periodically as the blade rotates (this is illustrated in appendix $B$ ). This results in periodically varying lift forces. The major component of the lift forces complete an excitation cycle once per revolution, and are referred to as first order or IP excitation forces. However, as explained in appendix $B$, there also are components of the lift forces that complete an excitation cycle twice per revolution. These are referred to as second order or $2 \mathrm{P}$ excitation forces.

The wind tunnel experiment of this investigation was done in two parts. First, an eight blade inherently mistuned rotor was tested in off-axis flow. Then, every other blade was removed from the rotor, and replaced with a blade of different frequencies and mode shapes. This replacement blade was the same as the original, except for the ply orientations of its composite material. This difference resulted in the change of frequencies and mode shapes. The original rotor was now intentionally mistuned. This rotor was also tested in off-axis flow.

This paper describes the experiment and compares vibratory strain amplitudes of the blades in the two mistuned rotors described above. Also, these strain amplitudes are compared to previously measured strains from a third rotor (ref. 3). The third rotor was inherently mistuned and had eight blades of the type used to intentionally mistune the first rotor of this experiment. 


\title{
DESCRIPTION OF THE EXPERIMENT
}

\author{
Test Rig Instailation
}

The experiment was conducted in the Lewis Research Center 8-by-6-ft (2.44-by-1.83-m) wind tunnel ( $\mathrm{fig}$. 1). The propfan models were mounted on an air turbine driven, single rotation, isolated nacelle test rig. This rig was ceiling strut mounted. The off-axis or angled flow was obtained by remotely tilting the propeller shaft in pitch with respect to the free stream. Eight blades were mounted in a relatively rigid hub.

\section{Models and Procedures}

Two existing propfan research models, the SR3C-X2 and SR3C-3 (refs. 4 to 6), each of $0.62 \mathrm{~m}(2 \mathrm{ft})$ diameter, were used for the experiment. The models had the same geometry and material but differed in natural frequencies and mode shapes. This difference was designed into the blades by varying the ply orientations of the laminated graphitelepoxy unidirectional blade material. Both models had 80 percent of the plies in the blade pitch axis $\left(0^{\circ}\right)$ direction, as shown in figure 2 . The remaining plies were distributed at the $\pm 22.5^{\circ}$ directions for the $-X 2$ blades, and at the $\pm 45.0^{\circ}$ directions for -3 blades. The aeroelastic characteristics of the blades differed because of frequency and mode shape differences between them. The -X2 blades were designed for classical flutter experiments and the -3 blades for aeroelastic response experiments. The $-x 2$ and -3 models were wind tunnel tested prior to the present experiment and performed as designed. Experimental and analytical results were reported in references 4 to 6 for the previous flutter experiments, and in references 2 and 3 for the previous aeroelastic response experiments.

The present experiment was done in two parts. First, an eight bladed $-X 2$ rotor was tested in off-axis flow. Then, every other $-x 2$ blade was removed from the rotor, and replaced with an -3 blade. This rotor was intentionally mistuned, based on the different frequencies and mode shapes of the blades (to be discussed later), whereas the rotor of eight $-x 2$ blades had inherent mistuning from manufacturing differences of the blades. The intentionally mistuned rotor also was tested in off-axis flow.

Three eight bladed rotor configurations will be referred to in this paper (fig. 3). One rotor has all - X2 blades, and another has all -3 blades. These are the uniform rotors, and will be called the $-x 2$ and -3 rotors, respectively. $A$ third rotor has both $-\times 2$ and -3 blades, in alternate rotor positions. This rotor will be called the mixed rotor. Blades are identified by the hub positions they occupy in the rotor, as shown in figure 3 .

The test variables were shaft tilt angle, rotor speed and blade pitch angle (the acute angle that the blade chord makes with the plane of rotation at the 0.75 blade radius). Blade vibratory strain data was recorded at combinations of the following conditions: at blade angles of $48.1^{\circ}, 56.1^{\circ}, 61.2^{\circ}$ and $68.0^{\circ}$; at shaft tilt angles of $4^{\circ}, 8^{\circ}$, and $12^{\circ}$; and during dwells at constant rotor speeds from windmilling to $9000 \mathrm{rpm}$. All testing was done at a tunnel Mach number of 0.36 . The test procedure was to lock the blade pitch angle manually and then start the tunnel. When the tunnel speed was set, the rotor shaft was tilted and power was applied to the rotor. 
Blade mounted foil strain gages provided the vibration data. Each blade had at least one gage at a common location, since the effect of mistuning on all the blades was being studied. Only dynamic strain signals were recorded and monitored during the testing. Figure 4 shows the instrumentation installed on the blades of the $-x 2$ and mixed rotors of this experiment. Also shown are the locations of strain gages installed on the blades of the -3 rotor of the previous experiment. Gage 1 is located inboard and gage 2 near to the tip. Both gages have uniaxial grids. The gages were located to provide good strain sensitivity to the first four natural blade modes, as determined by finite element analyses.

\section{Propfan Blade Campbell Diagrams and Mode Shapes}

Campbell diagrams (fig. 5) will help explain the blade responses that were experienced during the experiment and natural frequency differences between the blades. These were obtained by finite element analyses. Only the first two natural frequencies are shown, since the higher modes contribute little to the response of the blades for the conditions of this experiment. Also shown are the 1-per-rev (IP) and 2-per-rev (2P) excitation order lines, since these were the dominant excitations present during the experiment. The curves for both blades show similar variation of the first and second modes with rotational speed. The first mode frequencies of both blades are very close, but the second mode frequency of the -3 blade is higher than that of the $-X 2$ blade, i.e., the -3 blade is stiffer in the second mode. As explained in appendix $B$, the major blade excitation with the rotor tilted in the freestream occurs at a frequency of IP. Since the first blade mode is nearest to the IP excitation order line it should be the mode with the dominant response to a $1 \mathrm{P}$ excitation. Also, since the first mode frequency approaches the $I P$ line as rotational speed increases, the IP blade response should increase with increasing rotational speed. The data to be presented follows this expected trend.' It should also be noted that dynamic pressure increases with rotational speed and also contributes to the increase in blade response. Figure 5 shows that there is a crossing of the first mode and the $2 \mathrm{P}$ excitation order line. The data will show that the blades in the $-X 2$ rotor responded with larger amplitudes than the blades in the mixed rotor near this crossing, and that the crossing actually occurs at about $8000 \mathrm{rpm}$ instead of the calculated value of about $6000 \mathrm{rpm}$.

The first two natural mode shapes of the $-x 2$ and -3 blades differ and the differences are part of the mistuning present in the mixed rotor. The differences can be seen from photos of hologram mode shape contours of a $-x 2$ and -3 blades (fig. 6). The black fringes represent contours of constant displacement, and the whitest fringes are node lines. The blade modes consist of coupled motions, primarily because of blade sweep. The first mode of the $-\times 2$ blade has greater torsion/bending coupling than the -3 blade. This is indicated by the greater slope of the displacement contours. The second modes of the blades have contours at different spacing and node lines of different shape. There were also small mode shape differences between the blades of the uniform rotors, but these are not shown. 
Levels of Frequency Mistuning in the Rotors

The variation of the bench measured individual blade frequencies about the mean blade frequency was used as the measure of the frequency mistuning in each rotor. The variation of the natural frequencies for the first two modes of the blades in the $-X 2$ rotor and the mixed rotor is shown in figure 7 (this information was not available for the uniform -3 rotor). Also, listed for each mode are the mean frequency $(F)$ and the coefficient of variation (standard deviation divided by the mean frequency, $S / F$ ). The two modes of the $-X 2$ rotor have a maximum frequency that is 1.03 times the mean, and a coefficient of variation of 0.0245 and 0.0153 , respectively. The first mode frequencies of the blades in the mixed rotor have slightly less variation about the mean than those of the $-\times 2$ rotor (the measured first mode frequencies of the $-X 2$ and -3 blades were very close). Whereas, the second mode frequencies have significantly greater variation of an alternate pattern about the mean. Therefore, the mixed rotor has greater frequency mistuning of an alternate nature in the second mode, and less frequency mistuning in the first mode, compared to the $-X 2$ rotor.

\section{DISCUSSION AND RESULTS}

The results will be presented in three parts. First, an overview of the IP vibratory blade amplitudes will be given at typical test conditions to show: (1) how the IP vibratory amplitudes of the individual blades in the rotors compare, and (2) how the shaft tilt angle and blade angle affect the mean IP amplitude of the blades in the rotors. Then, statistical data plots of the ip vibratory amplitudes will be given in terms of the ratio of the maximum amplitude to the mean and the coefficient of variation for all the test conditions. Last, the $2 \mathrm{P}$ vibratory strain amplitudes will be compared for a blade common to both the $-\mathrm{X} 2$ and mixed rotors.

\section{Individual Blade IP Strain Amplitude Variation}

A typical variation of the IP strain amplitude of the blades in the uniform and mixed rotors with rotational speed is shown in figure 8 . Data are shown for the eight blades in the $-x_{2}$ rotor, and the eight blades in the mixed rotor. Also, data are shown from reference 3 , for three blades in a -3 rotor (only three -3 blades were strain gaged). The figure shows that the IP blade strain amplitudes of the $-\times 2$ rotor are larger in magnitude and variation than those of the -3 rotor. However, in the mixed rotor the amplitude of the $-\times 2$ blades drop significantly and are below those of the -3 blades, and the -3 blades have relatively small changes in amplitude compared to the blades in the uniform -3 rotor. The expected trend of an increase in IP strain amplitude with rpm (discussed earlier) is shown by the data. Note, that if only a few blades in the $-x 2$ rotor had been monitored, the maximum responding blades may have been missed. The large reduction in the $-\times 2$ blade $1 P$ amplitude, from the uniform $-x 2$ to the mixed rotor, occurred although the dominant responding mode, the first, is closely frequency tuned for both the rotors. This suggests that the differences in the mode shapes and second mode frequencies of the blades in the mixed rotor had this effect. 
The hub position of the blade associated with each strain amplitude is identified in figure 8 , for the $-x 2$ and the mixed rotors at 8000 and $8300 \mathrm{rpm}$, respectively. This was done to illustrate that the blade responses could not be predicted intuitively based on the variation. of blade natural frequencies shown in figure 7 .

\section{Comparison of Mean, Maximum and Minimum IP Amplitudes}

A comparison of the mean and range of the iP amplitudes for the $-X 2$ and the mixed rotors can be made from figure 9 . Figures $9(a)$ and (b) are for strain gage 1 and represent part of the data in figure 8 . The effect of the intentional mistuning on reducing the response of the blades is demonstrated here. Also, the rate of increase of the mean IP amplitude is smaller for the mixed than the $-\times 2$ rotor. This may be related to an effective increase in the aerodynamic damping. The same plots as above but for strain gage 2 are shown in figures $g(c)$ and $(d)$. Similar trends as discussed above for strain gage 1 also exist here. Note, figures $g(a)$ and $(c)$ show that the mean and maximum strain amplitudes of the $-X 2$ rotor are significantly higher for strain gage 2 than strain gage 1. Therefore, monitoring a root gage only in the $-X 2$ rotor would not have provided the total picture of what was occurring. Also note, figures $9(b)$ and (d) show that the mean strain amplitude of the mixed rotor is about the same for strain gages 1 and 2, but the maximum and range of the amplitudes are less for strain gage 2 than strain gage 1 . So, the intentional mistuning had a greater effect on the amplitude of strain gage 2 than gage 1.

\section{Effect of Tilt Angle on the Mean IP Amplitude}

The variation of the $1 P$ mean strain amplitude of the blades in the $-x_{2}$ and mixed rotors with rotational speed at three tilt angles is shown in figures $10(a)$ and (b), respectively. Theoretically, for a tuned rotor, the $1 P$ strain amplitude will increase linearly with tilt angle. The dashed lines in the figure represent a linear increase from the IP amplitudes at $4^{\circ} \mathrm{tilt}$. The data for the $-x 2$ rotor follows the expected linear trend very closely. However, the data for the mixed rotor have somewhat lower amplitudes than that of a linear increase. It is of interest to note this difference.

\section{Effect of Blade Angle on the Mean IP Amplitude}

The IP mean strain amplitude of the blades in the $-x 2$ and mixed rotors at four blade angles is shown in figures 11 (a) and.(b). The lowest amplitudes occur at the lowest blade angle for both rotors, at $48.1^{\circ}$. For the $-\mathrm{x} 2$ rotor there is an increase in blade stress with increasing blade angle at a constant rpm, but the amplitudes tend to converge at the three highest blade angles with increasing rotational speed. The mixed rotor amplitudes have more scatter at the three highest blade angles but have the same trends as the -X2 rotor data.

\section{Statistical Data Plots}

Statistical data regarding the effects of blade mistuning on propfan aeroelastic forced response is not currently available. Propfans are relatively 
new and the data has not been generated. In general, propfan blades will be manufactured to be within geometric tolerance limits, and the nature and degree of mistuning will not be a consideration of the rotor assembly. However, it has been shown in both analytical studies, and the present experiment, that mistuning can have significant and intuitively unpredictable effects on the amplitude of blade vibratory stresses. Therefore, designers require data to account for effects from mistuning that will be inherent in propfan rotors. Statistical data for the $-X 2$ rotor will be presented to provide some measured values for a propfan rotor with random mistuning. Random mistuning is typically present for turbomachinery rotors. Statistical data will also be given for the mixed rotor, with intentional frequency and mode shape mistuning, for comparison.

Effect of Blade Angle on the Maximum to Mean IP Amplitude Ratio

The ratio of the maximum to the mean $1 P$ amplitude for the blades in a mistuned rotor is one of the parameters that is of interest to designers. The variation of this parameter with rpm is given in figure 12 for the $-x 2$ and mixed rotors. Each plot is for conditions of one shaft tilt angle and four blade angles. For the $-X 2$ rotor, the highest $1 P$ amplitude ratio occurs at a shaft tilt angle of $4^{\circ}$ ( $\mathrm{fig} .12(\mathrm{a})$ ) and is 1.38, but at tilt angles of $8^{\circ}$ and $12^{\circ}$ the highest value drops to about 1.25 and 1.23 , respectively. The range of the IP amplitude ratio data is smaller at the higher shaft tilt angles. At a constant blade angle, the amplitude ratio first drops with increasing rpm but than levels off. In general, the IP amplitude ratio decreases with increasing blade angle at a constant rpm. However, this trend is less ordered at the lower shaft tilt angles (figs. 12(a) and $(c)$ ). For the mixed rotor, the amplitude ratio falls between 1.39 and 1.35 for the three shaft tilt angles (figs. $12(b),(d)$ and (f)). Here, at a constant blade angle, the amplitude ratio shows an increase with rpm, but a more random relationship with blade angle at a fixed ripm.

\section{Effect of Blade Angle on the Coefficient of Variation}

Plots of the coefficient of variation for both rotors are shown in figure 13. The coefficient of variation of the $-X 2$ rotor has a maximum range from 0.33 to 0.12 at a shaft tilt of $4^{\circ}$ ( $f i g .13(a)$ ), and a decreased magnitude and range at the higher shaft tilt angles (figs. 13(c) and (e)). In general, the coefficient of variation decreases with increasing blade angle at a fixed rpm. However, this trend becomes less ordered at a shaft angle of $4^{\circ}$. The coefficient of variation of the mixed rotor is lower than that of the $-\mathrm{X} 2$ rotor and falls in about the same range at the three shaft tilt angles, 0.22 to 0.12 . Also, the coefficient of variation of the mixed rotor is more random than that of the $-X 2$ rotor and shows the opposite variation with rpm at a constant blade angle, an increase instead of a decrease. It is of interest to note that similar trends exist in the data of figures 13 and 12 for both the $-x 2$ and the mixed rotors. 
There was a large difference in the $2 P$ response of the $-X 2$ blades in the $-\times 2$ and mixed rotors. This is illustrated in figure 14. The 2P amplitude variation with $\mathrm{rpm}$ for blade 1 in the $-x 2$ and mixed rotors is shown. As rotor speed increases the $2 \mathrm{P}$ amplitude of the blade in the $-X 2$ rotor increases at a faster rate than in the mixed rotor. At $8000 \mathrm{rpm}$ the amplitude of the blade in the mixed rotor is about half that in the $-\times 2$ rotor. So, the intentional frequency and mode shape mistuning resulted in a significant reduction in the $2 P$ response of the blade. A similar reduction occurred in the $2 P$ response of the other blades. A similar reduction occurred in the $2 \mathrm{P}$ response of the other $-X 2$ blades. The critical speed appears to be slightly above $8000 \mathrm{rpm}$. However, figure 5 shows the calculated critical speed at about $6000 \mathrm{rpm}$.

\section{CONCLUDING REMARKS}

The results of mistuning for propfans, like other systems, are difficult to generalize because they depend on the characteristics of the particular system. In this paper, the measured aeroelastic response of the blades for two mistuned propfan rotors have been compared over a wide range of inflow angles, rotor speeds and blade angles. The $-x 2$ rotor had inherent random mistuning, and the mixed rotor had intentional alternate mistuning. If the blades of the -X2 rotor were identical then, theoretically, the aeroelastic response of all the blades would have been the same. However, because of inherent mistuning, the blades of the $-x 2$ rotor had a large variation in aeroelastic response that could not be intuitively predicted. Since similar variations may exist for other propfans with inherent mistuning, it is recommended that mistuning be considered in designing propfans for aeroelastic forced response. The following was observed from the data.

1. Intentional alternate mistuning caused: a large reduction in the $1 P$ and $2 P$ amplitudes of the higher responding $-X 2$ blades, a relatively small change in the $1 P$ amplitudes of the lower responding -3 blades, and a reduction in the rate of increase of the mean IP amplitude with rotational speed.

2. The mean IP amplitude increased with increasing blade angle, at a constant rotor speed, for the $-X 2$ rotor, and had a more random, although similar, trend for the mixed rotor. Also, the $-X 2$ rotor had a linear increase in the ip strain amplitude with shaft tilt angle but the mixed rotor did not.

3. For the $-x 2$ rotor, the variation of the maximum to mean $1 P$ amplitude ratio decreased with increasing rotor speed at the lowest shaft tilt angle but was almost constant and of lower magnitude at the higher tilt angles. For the mixed rotor, the variation increased with increasing rotor speed and was about the same magnitude for all the shaft tilt angles.

4. In general, the coefficient of variation decreased with increasing blade angle for both the rotors but in a more random fashion for the mixed rotor. The coefficient of variation decreased and leveled off for the $-X 2$ rotor and increased for the mixed rotor with increasing rotor speed. 


\section{APPENDIX A}

\section{NOMENCLATURE}

$R$ rotor tip radius

$r$ radius to blade section

$\mathrm{t} \quad \mathrm{time}$

$V$ velocity of the freestream

W resultant velocity at a blade section

$\alpha \quad$ blade section angle of attack

$\beta \quad$ blade pitch angle

$\phi \quad$ geometric helix angle

$\Psi$ angle of the freestream velocity with respect to axis of rotation or shaft tilt angle

$\Omega \quad$ angular velocity of rotor 


\section{APPENDIX B}

\section{EXPLANATION OF DYNAMIC BLADE EXCITATION FOR A PROPELLER ROTOR IN OFF-AXIS FLOW}

The generation of dynamic blade excitation from off-axis flow is illustrated in the schematic diagrams of figure $B-1$. Figure $B-1(a)$ shows a side view of a propfan rotor in a uniform, steady free stream of velocity $V$ and at an angle $\psi$ from the axis of rotation. The angle $\psi$ is referred to as the shaft tilt angle. The components of $V$ along the axis of rotation and in the plane of rotation are $V \cos \psi$ and $V \sin \psi$ respectively. Only velocity components of airflow in the plane of rotation and normal to blade sections will be considered for blade lift. Blade sweep will be neglected for this explanation for simplicity. The magnitude of the in-plane velocity component normal to sections of the blade varies with the position of the blade during rotation. This variation is illustrated in the front view of figure $B-1(a)$. At the $0^{\circ}$ and $180^{\circ}$ positions the in-plane component of velocity is radial and does not contribute to blade lift. As the blade rotates to the angular position $\Omega t$ the circumferential component of the freestream airflow normal to the blade section is given by $V$ sin $\psi$ sin $\Omega t$ and is in the same direction as the relative velocity due to rotation. As shown in figure $B-1(a)$, when the blade reaches the angular position of $90^{\circ}$ and $270^{\circ}$, all of the in-plane freestream component is normal to the blade section, and the relative velocity due to rotation is in the same sense at $90^{\circ}$, but in the opposite sense at $270^{\circ}$.

Figure $B-1(b)$ illustrates the velocity diagram for a typical blade section at $a$ blade angle $\beta$. The velocity of the airflow and the angle of attack as seen by the blade at an angular position $\Omega t$ are denoted by $W_{\Omega t}$ and a $a t$, respectively. As shown in the figure, both the relative velocity and the angle of attack are periodic functions of the angular position, and complete an excitation cycle once per revolution of the rotor. In unstalled conditions, the lift forces are proportional to the angle of attack and to the square of the relative velocity. Hence, the rotating blade experiences periodic lift forces due to the off-axis flow. The variation of angle of attack and the relative velocity with angular position results primarily in forces at a IP excitation frequency, but there are also smaller force components at a $2 \mathrm{P}$ excitation frequency. Excitations at frequencies above $2 P$ are negligible when the tilt angle is small. The $2 P$ frequency lift components arise from the periodic but not purely sinusoidal variation of the angle of attack and from the dependence of the lift on the square of the relative velocity. Thus, off-axis flow conditions result in both $1 P$ and $2 P$ excitations acting on the blades. Note, that the varying lift forces from the off-axis flow cause the blades to experience a dynamic excitation, even though the rotor is in a steady, uniform flow field. 


\section{REFERENCES}

1. Mehmed, 0 , et al, "Bending-torsion Flutter of a Highly Swept Advanced Turboprop", NASA TM 82975, October, 1981.

2. Smith, A.F., "Analysis And Test Evaluation Of The Dynamic Response And Stability of Three Advanced Turboprop Models At Low Forward Speed", NASA CR - 175026, December, 1985.

3. Smith, A.F., "Dynamic Response and Stability Of A Composite Prop-Fan Model", NASA CR - 179528, October, 1986.

4. Turnburg, J.E., "Unstalled Flutter Stability Predictions And Comparisons To Test Data For A Composite Prop-Fan Model", NASA CR - 179512, October, 1986

5. Mehmed, 0 and Kaza, K.R.V., "Experimental Classical Flutter Results of a Composite Advanced Turboprop Model", NASA TM 88792, July, 1986

6. Kaza, K.R.V., et al, "Analytical and Experimental Investigation of Mistuning in Propfan Flutter", NASA TM 88959, Apri1, 1987

7. Kaza, K.R.V., et al; "Aeroelastic Response of Metallic and Composite Propfan Models in Yawed Flow", AIAA Paper No. 88-3154 ,paper for presentation at the AIAA/ASME/SAE 24th Joint Propulsion Conference and Exhibit, July 11-14, 1988, Boston, Massachusetts

8. Ewins,D.J.; "Bladed-Disc Vibration - A Review of Techniques and Characteristics", Recent Advances in Structural Mechanics, University of South Hampton, U.K., 1980, pp.187-210

9. Srinivasan,A.V. and Fubunmi, J.A.; "Cascade Flutter Analysis of Cantilevered Blades", Journal of Engineering for Gas Turbines and Power, vol.108, no.1, Jan. 1984, pp.34-43

10. Kaza, K.R.V. and Kielb, R.E.; "Vibration and Flutter of Mistuned Bladed-Disk Assemblies", Journal of Propulsion and Power, vol.1, no.5, Sept. 1985, p.336 
ORIGINAL PAGE IS

OF. POOR QUALITY.

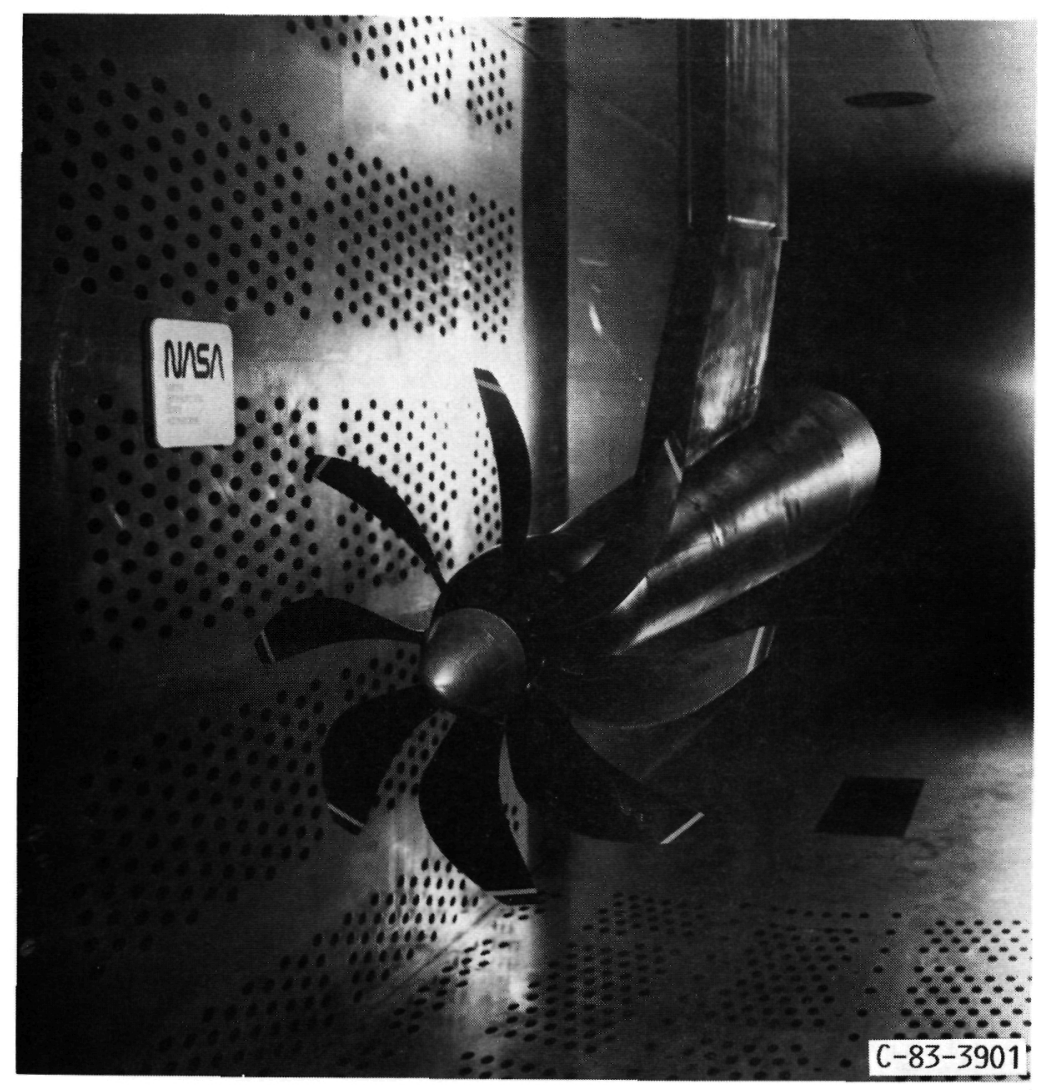

FIGURE 1. - SR3C-X2 PROPFAN MODEL WIND TUNNEL INSTALLATION.

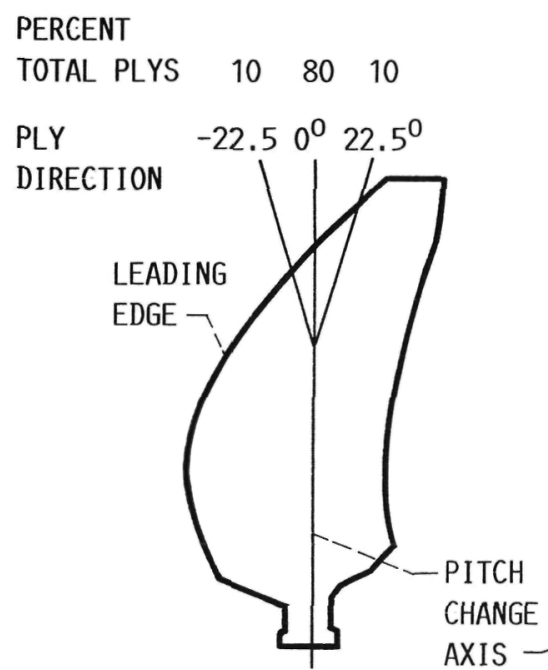

$\mathrm{SR}-3 \mathrm{C}-\mathrm{X} 2$

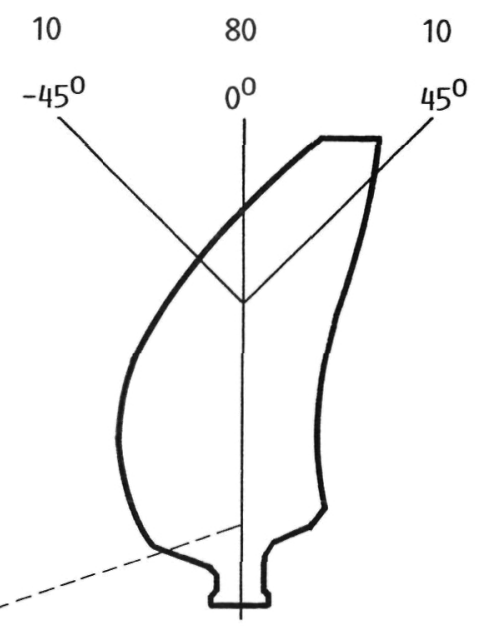

$S R-3 C-3$

FIGURE 2. - BLADE PLY DIRECTIONS. 

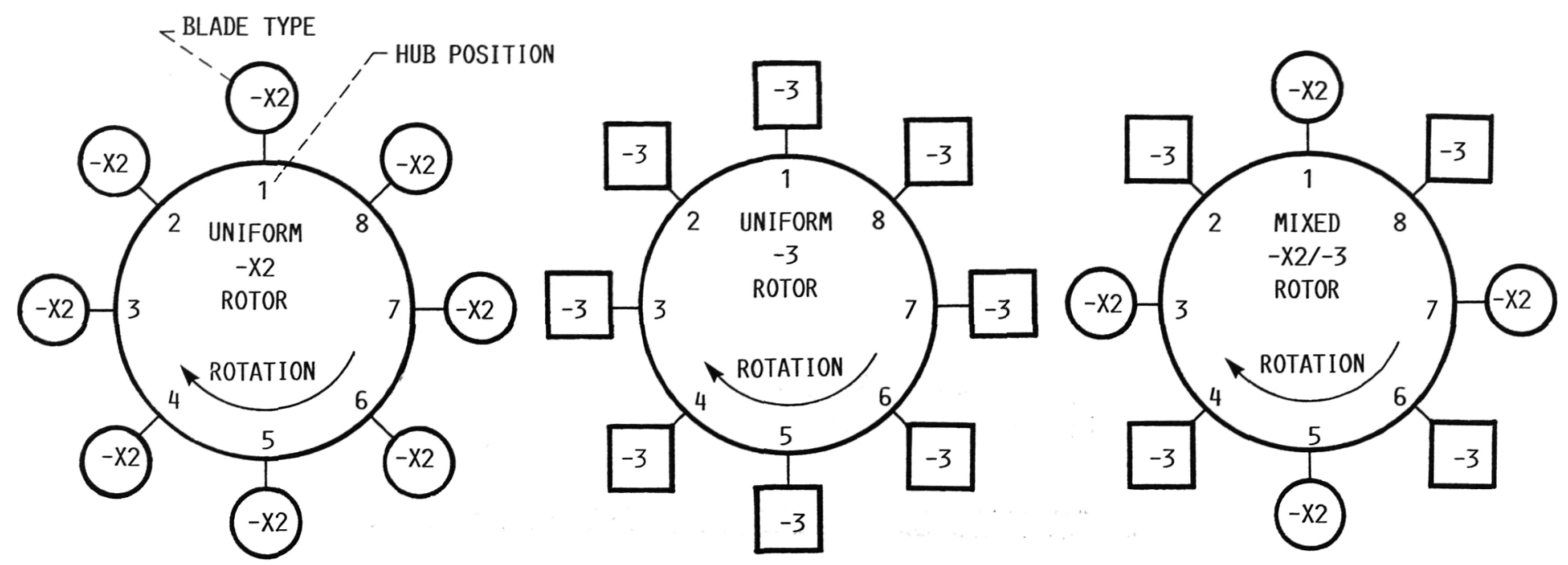

VIEWS LOOKING DOWNSTREAM

FIGURE 3. - SCHEMATIC DIAGRAMS OF UNIFORM AND MIXED ROTOR CONFIGURATIONS.
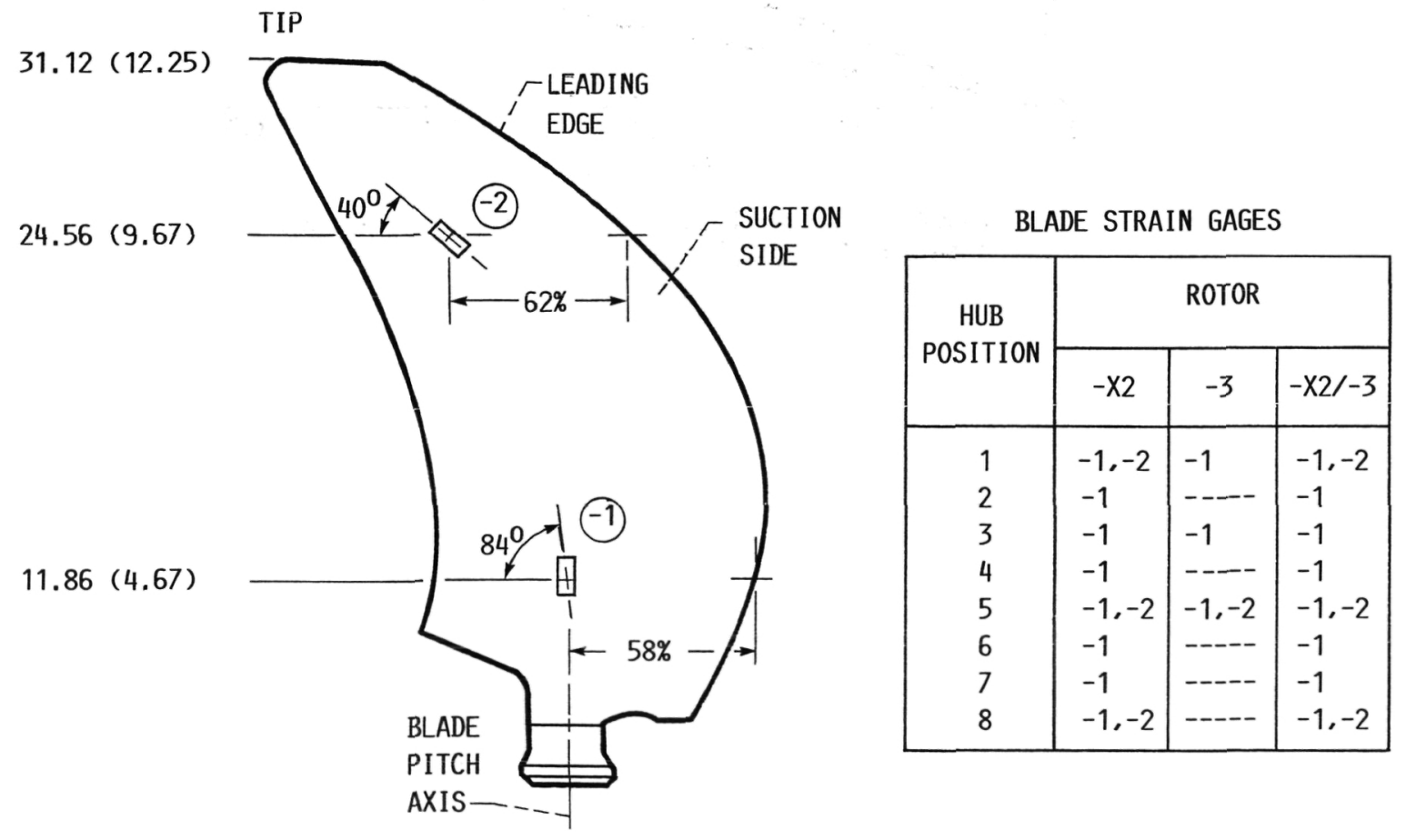

0

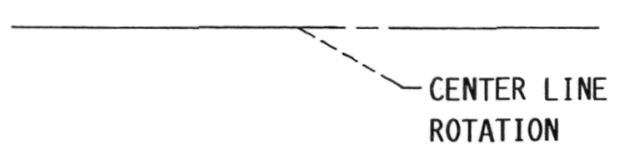

$\mathrm{CD}-88-34948$

FIGURE 4. - BLADE STRAIN GAGE INSTRUMENTATION. 


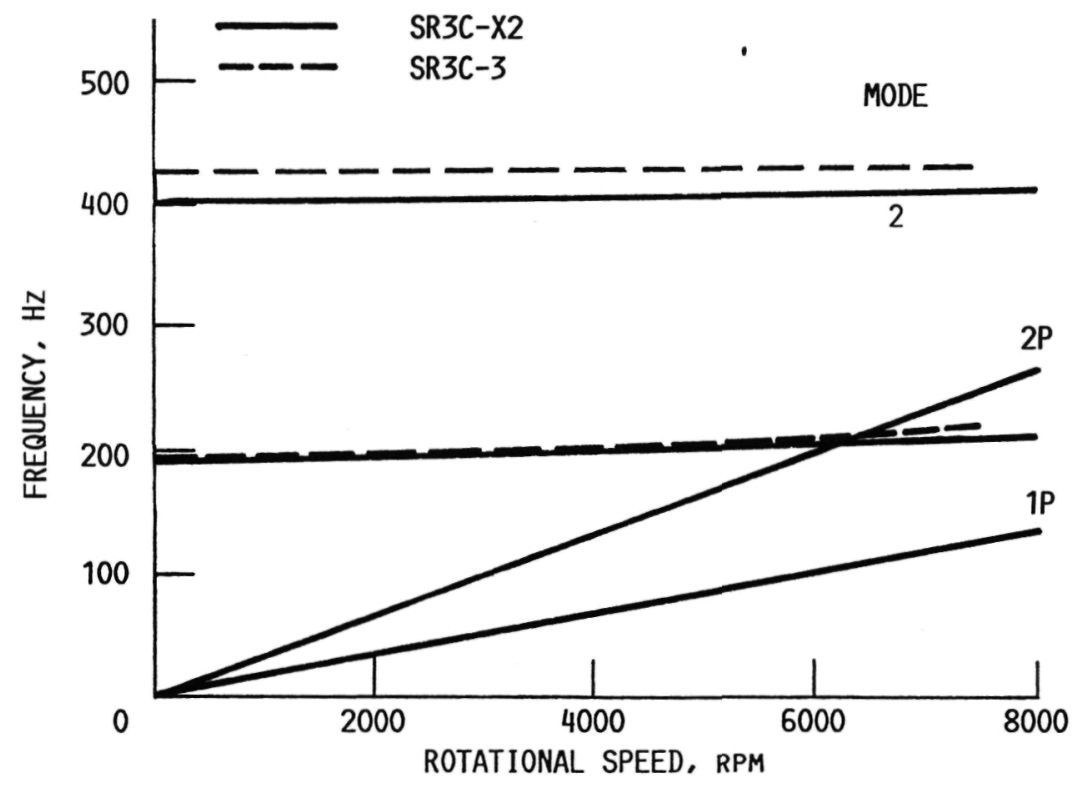

FIGURE 5. - CAMPBELL DIAGRAMS OF $-\mathrm{X} 2$ AND -3 BLADES, BLADE ANGLE $=61.2^{\circ}$. 
DRIGINAL PAGE IS

OR POOR QUALITY

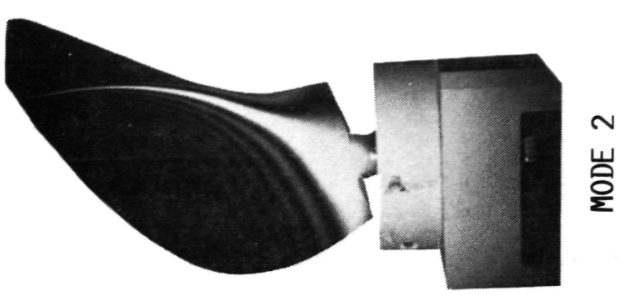

㭊
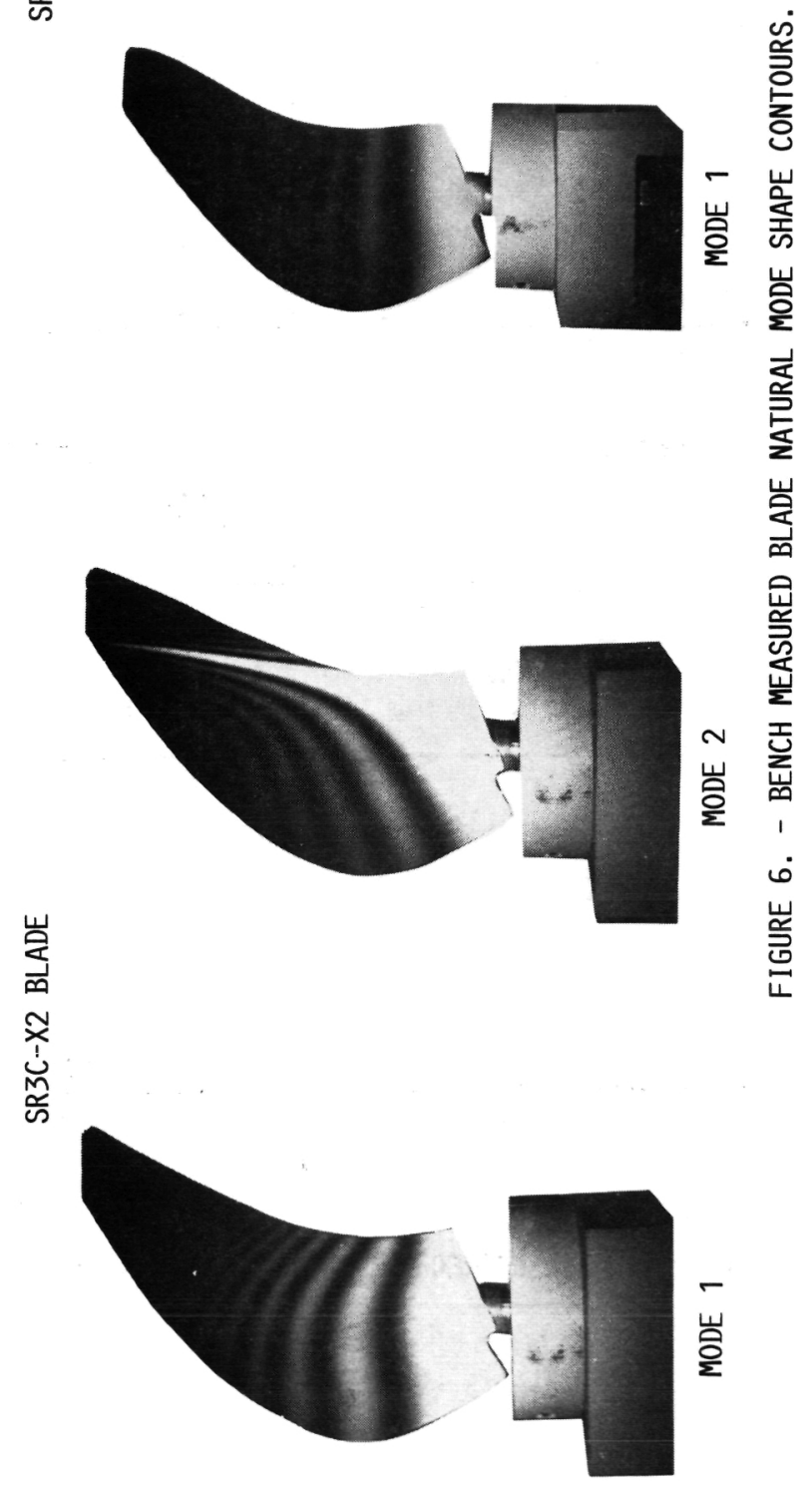


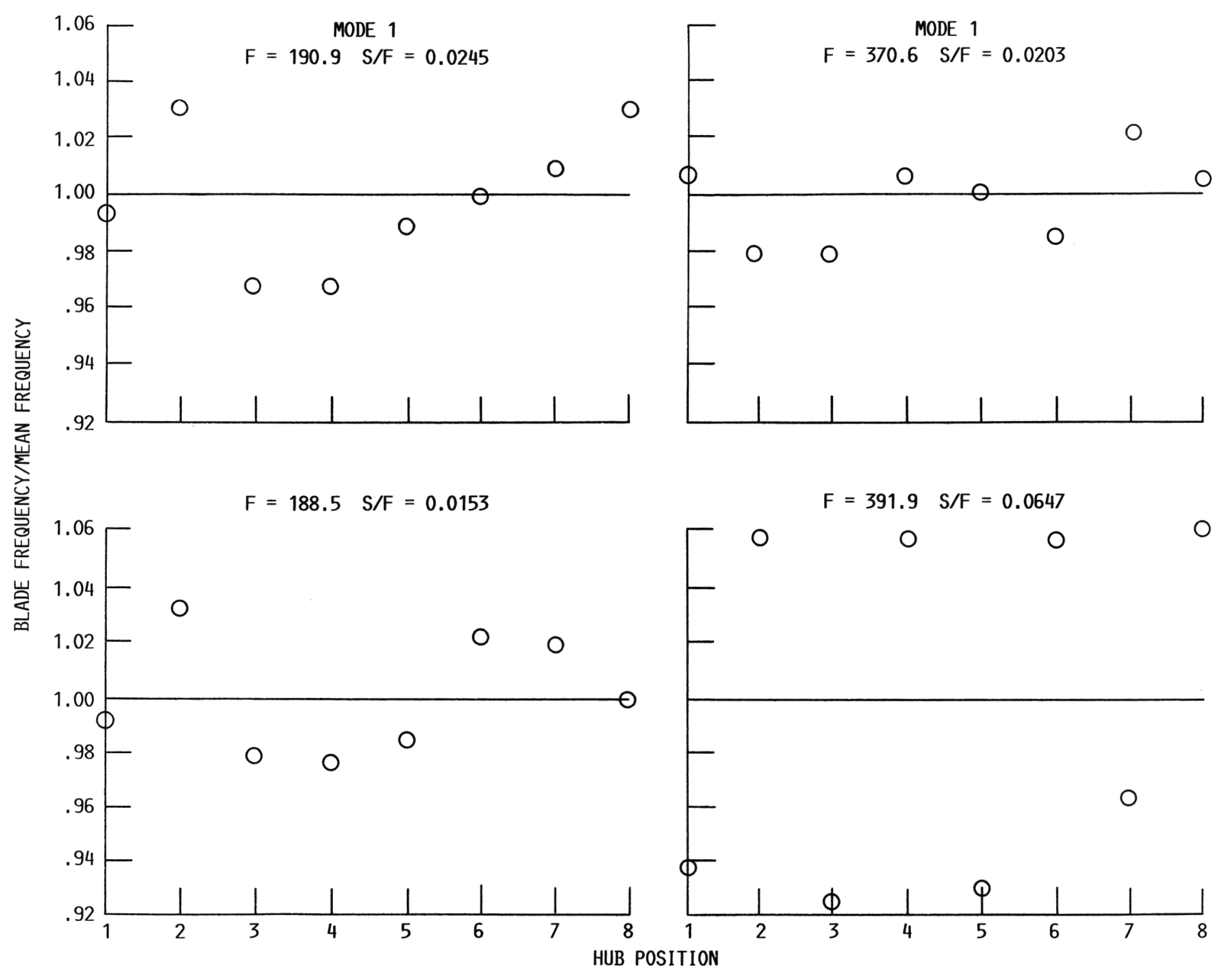

(a) $-X 2$ ROTOR.

(b) MIXED ROTOR.

FIGURE 7. - BLADE NATURAL FREQUENCIES FOR UNIFORM -X2 AND MIXED ROTORS. 


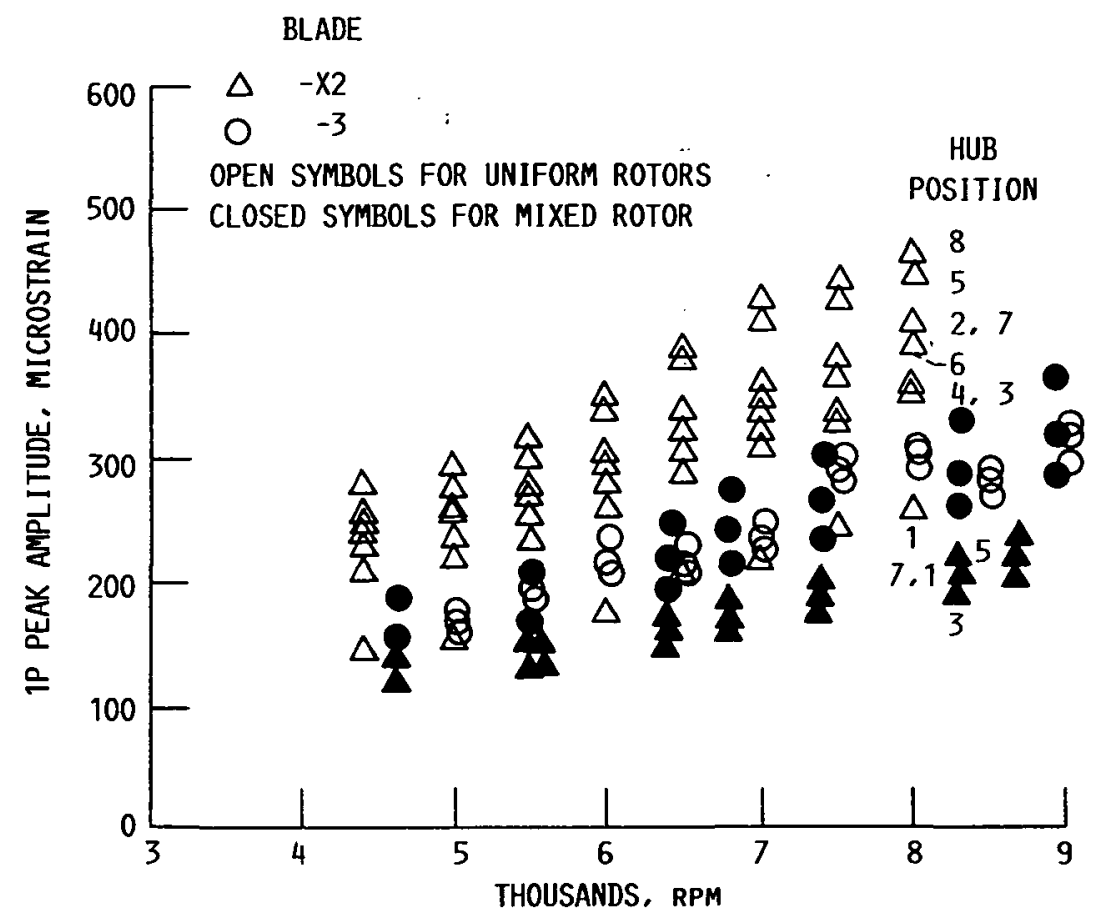

FIGURE 8. - IP AMPLITUDE FOR BLADES IN THE UNIFORM AND MIXED ROTORS, TILT $=8^{\circ}$. BLADE ANGLE $=48.1^{\circ}$ FREESTREAM MACH $=0.36$, GAGE $=1$.
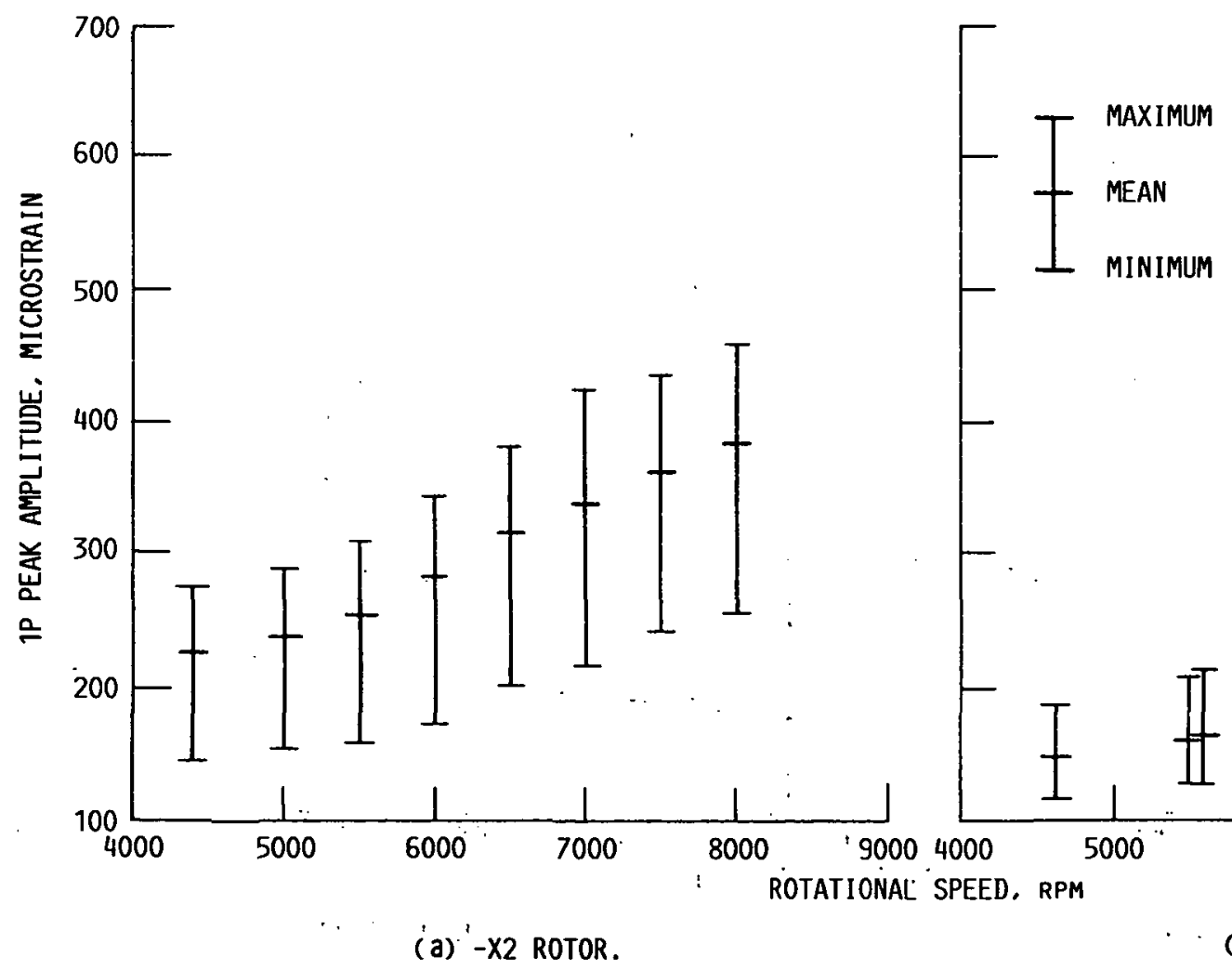

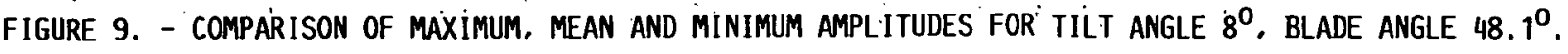




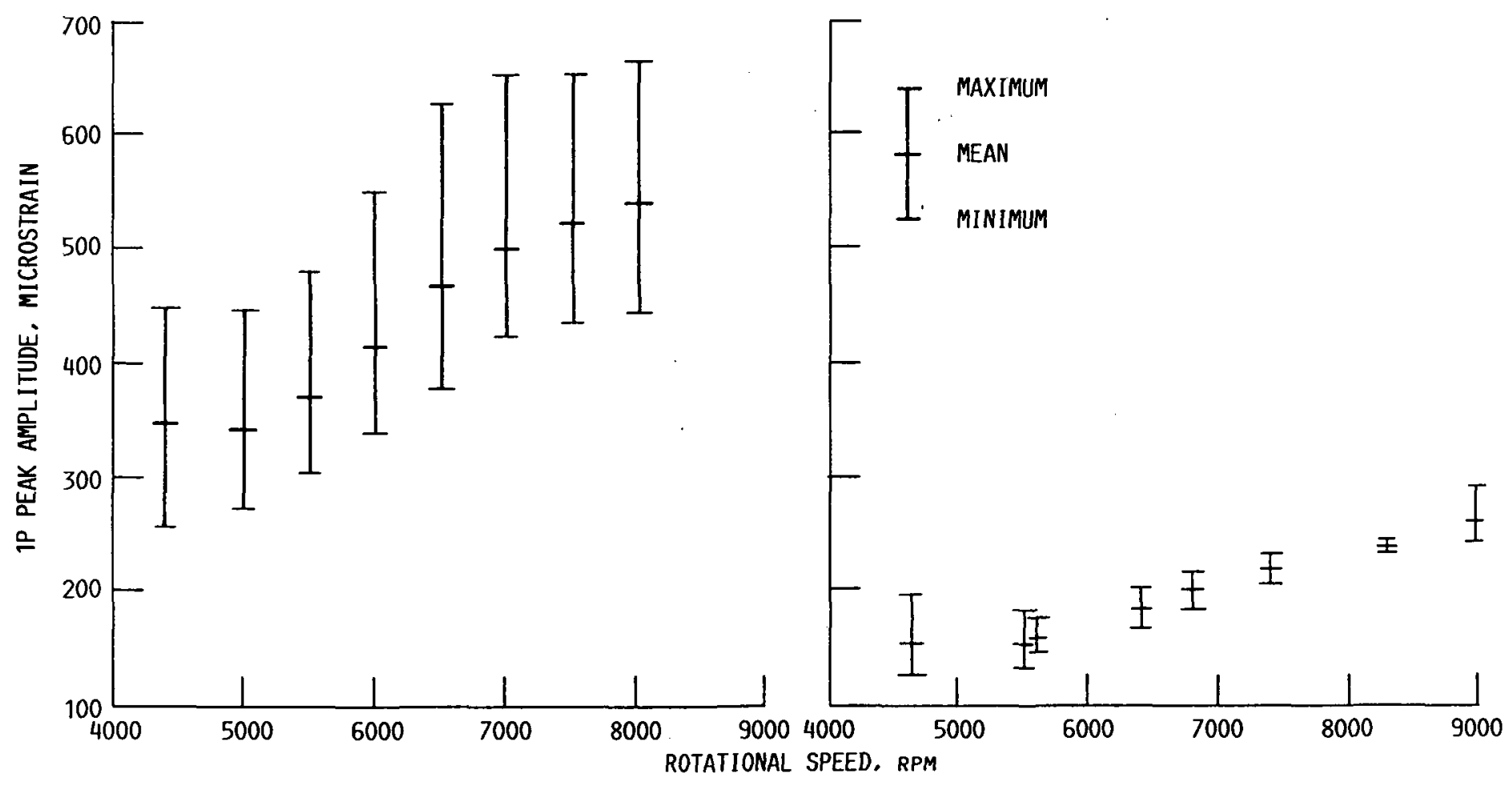

(c) - X2 ROTOR.

(d) MIXED ROTOR.

FIGURE 9. - CONCLUDED.

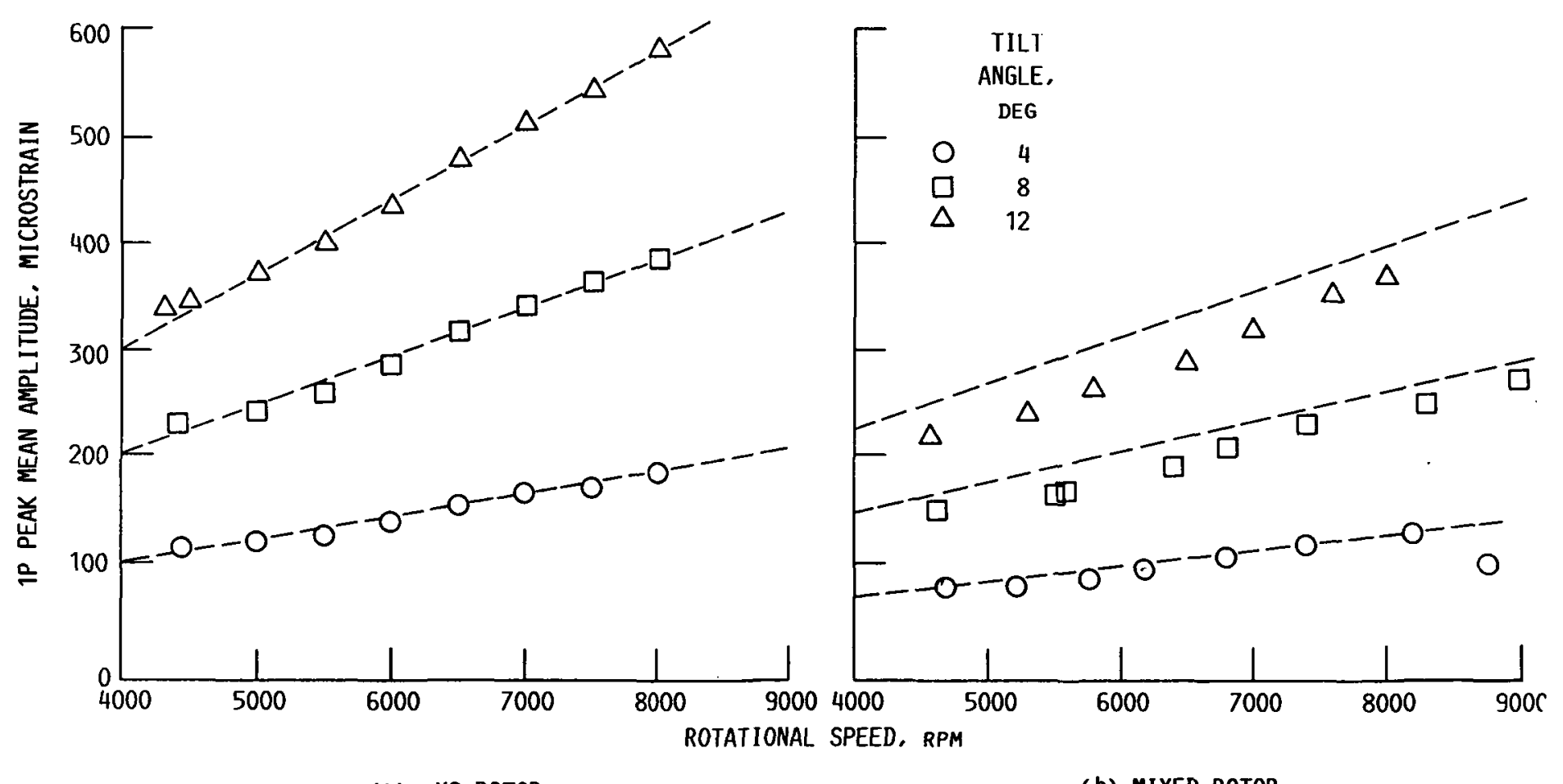

(a) $-X 2$ ROTOR.

(b) MIXED ROTOR.

FIgURE 10. - EFFECT OF TILT ANGLE ON 1P AMPLITUDE. BLADE ANGLE 48. ${ }^{\circ}$ AND STRAIN GAGE 1. 


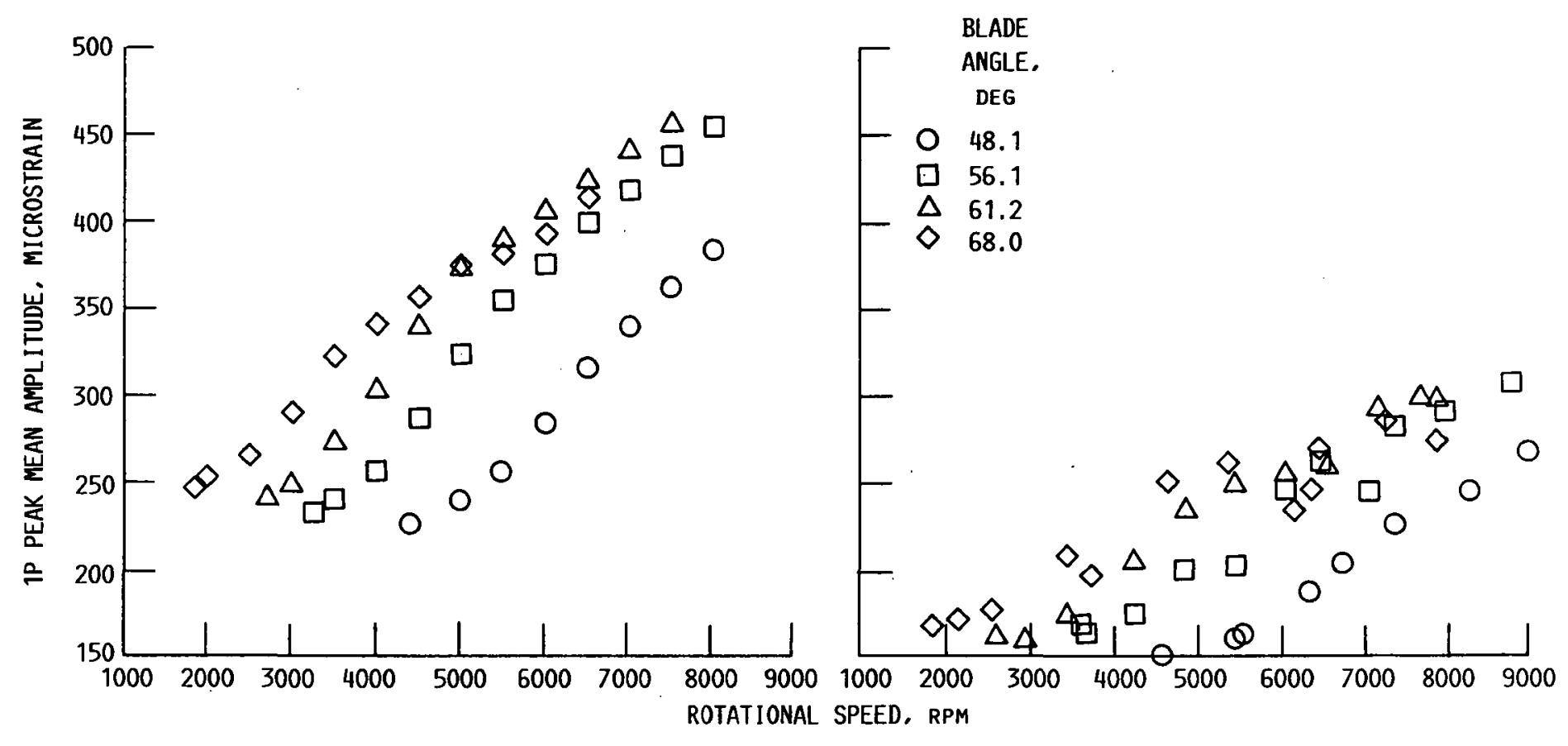

(a) $-X 2$ ROTOR.

(b) MIXED ROTOR.

FIgURE 11. - EFFECT OF BLADE ANGLE ON THE IP AMPLITUDE, TILT ANGLE $8^{0}$ aNd STRAin gaGe 1. 
$-X 2$ ROTOR

MIXED ROTOR

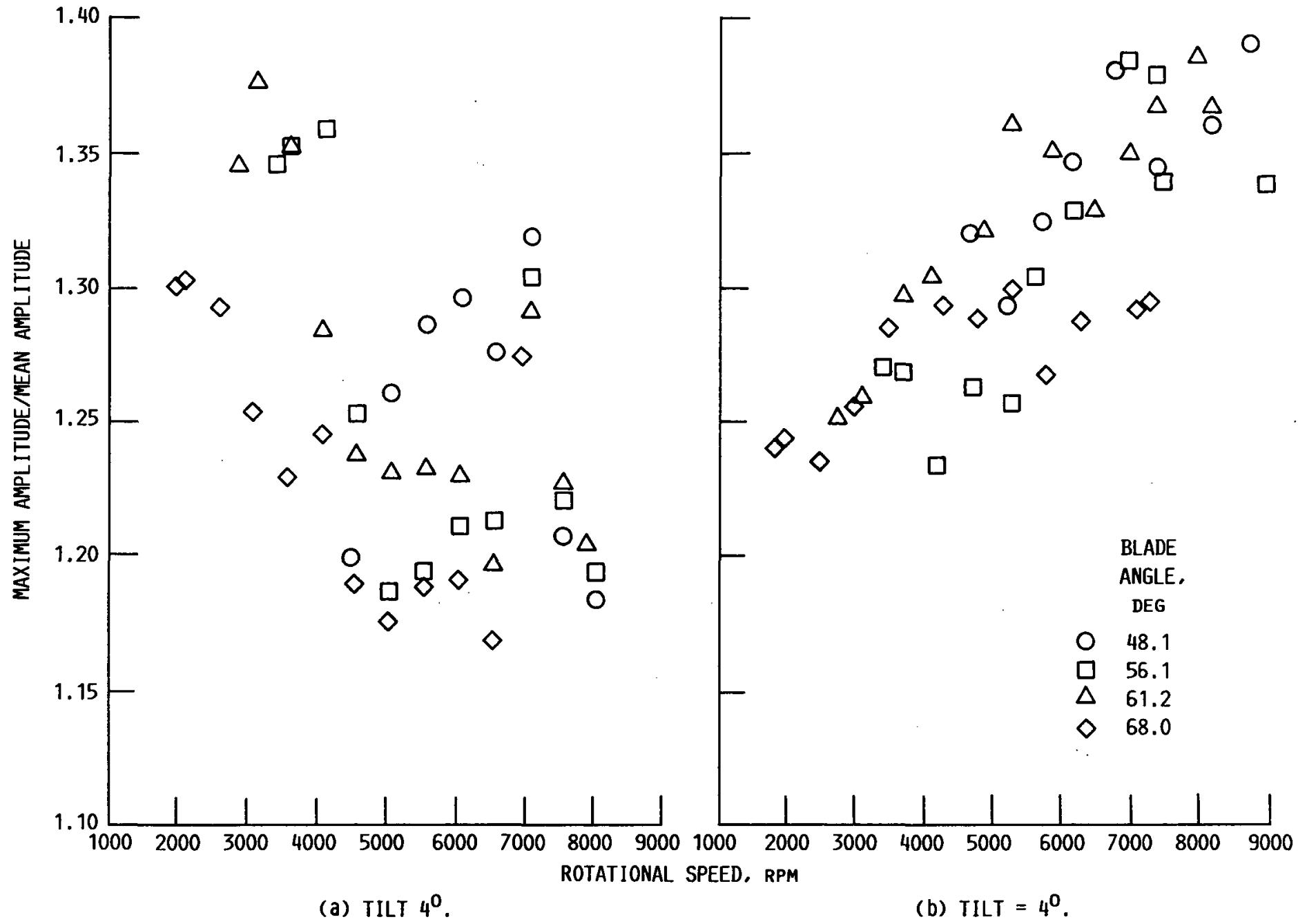

FigURE 12. - EFFECT OF BLADE ANGLE ON THE MAXIMUM tO MEAN IP AMPLITUDE RATIO, STRAIN gage 1. 


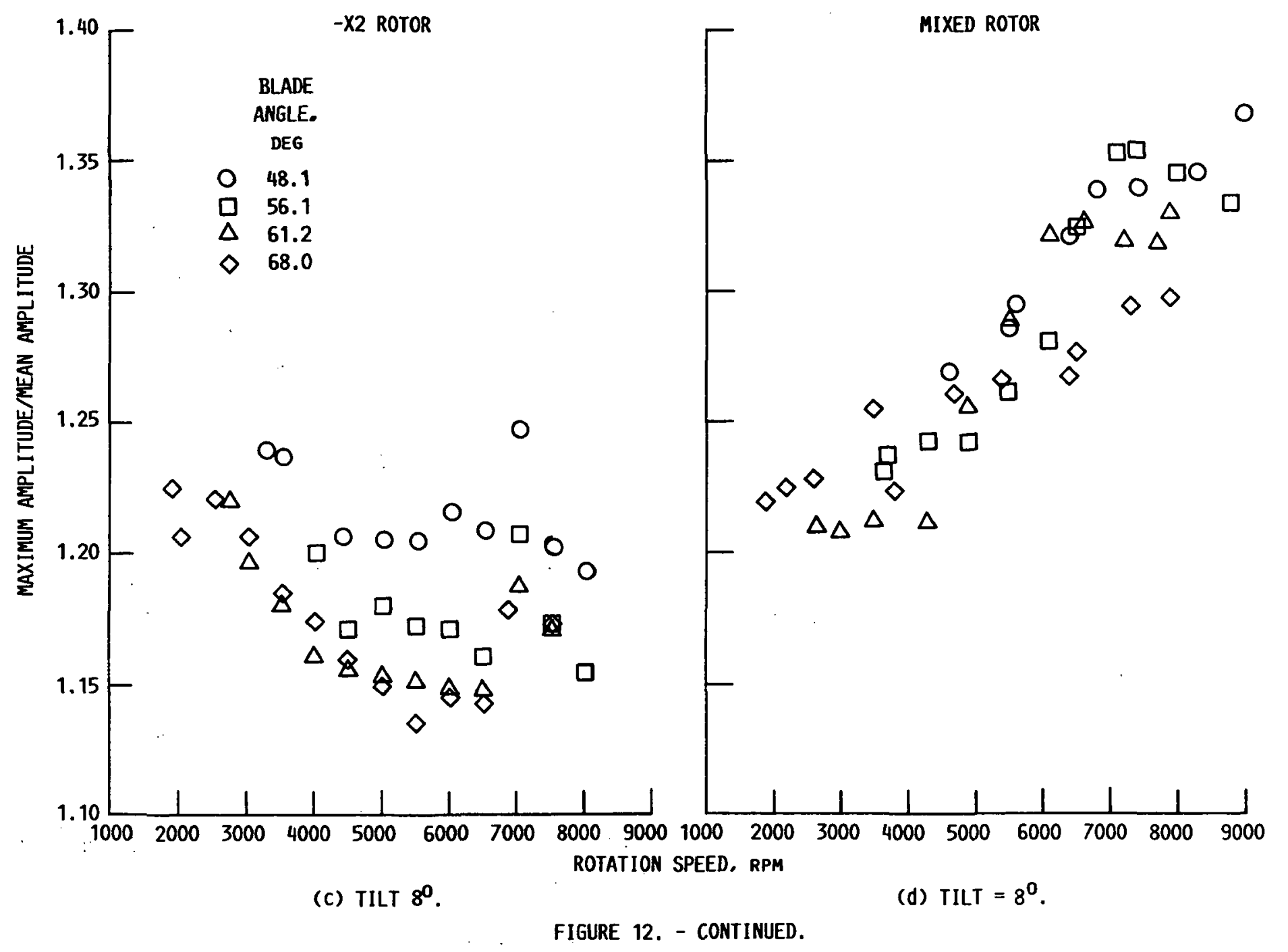




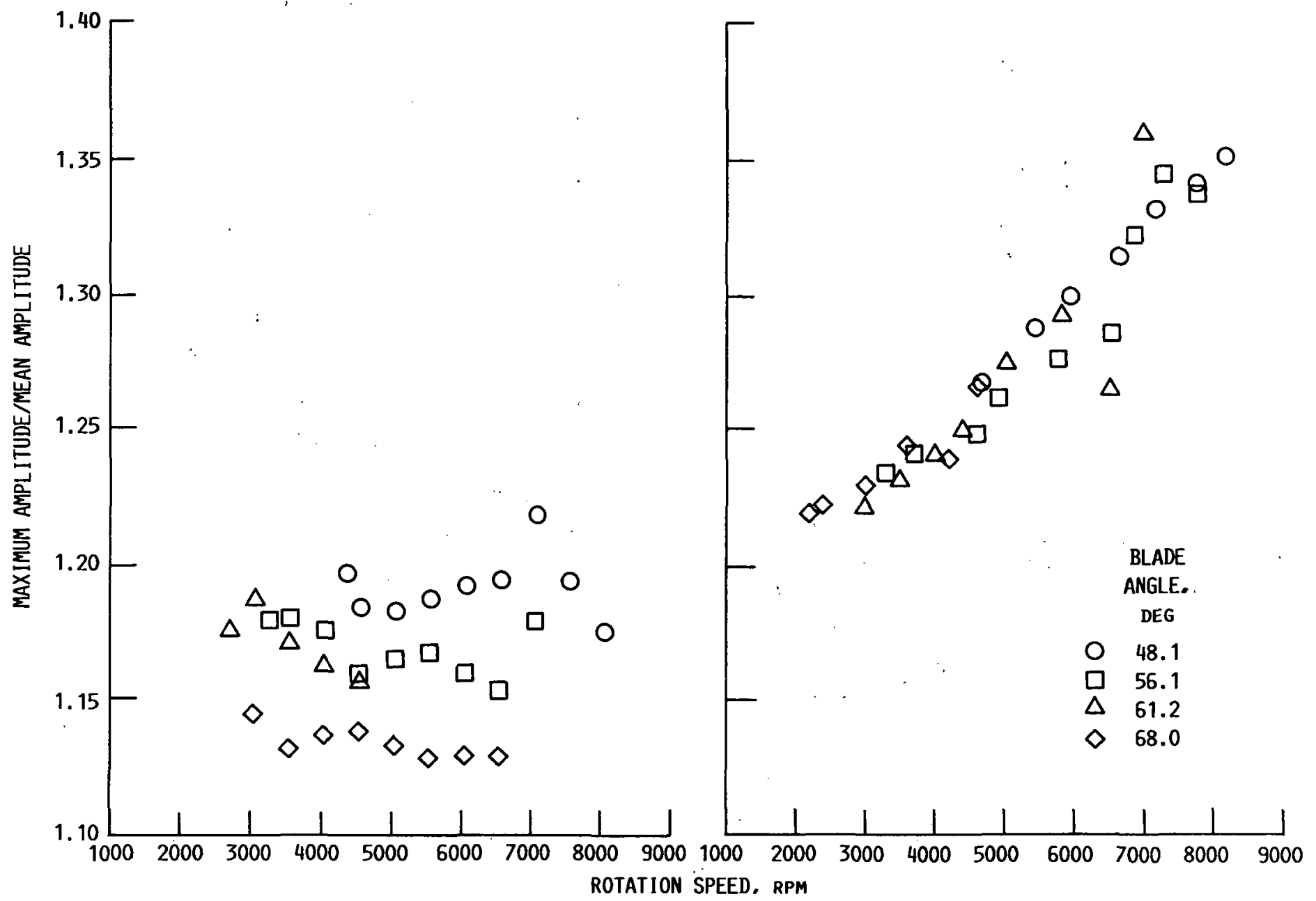

(e) TILT $=12^{\circ}$.

(f) TILT $=12^{\circ}$.

FIGURE 12. - CONCLUDED, 


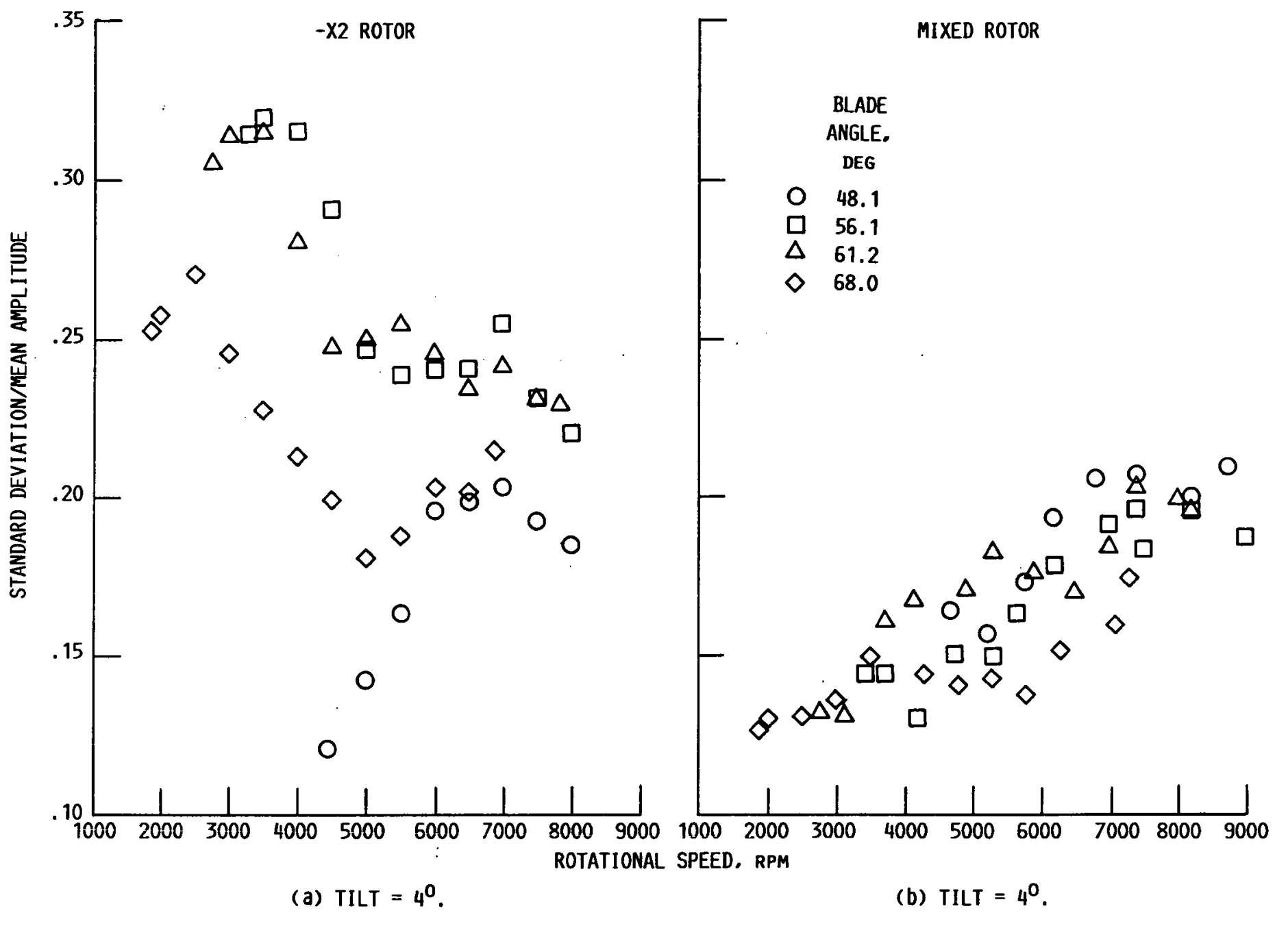

FIGURE 13. - EFFECT OF BLADE ANGLE ON 1P PEAK AMPLITUDE COEFFICIENT OF VARIATION. STRAIN GAGE 1. 
$-\mathrm{X} 2$ ROTOR

MIXED ROTOR

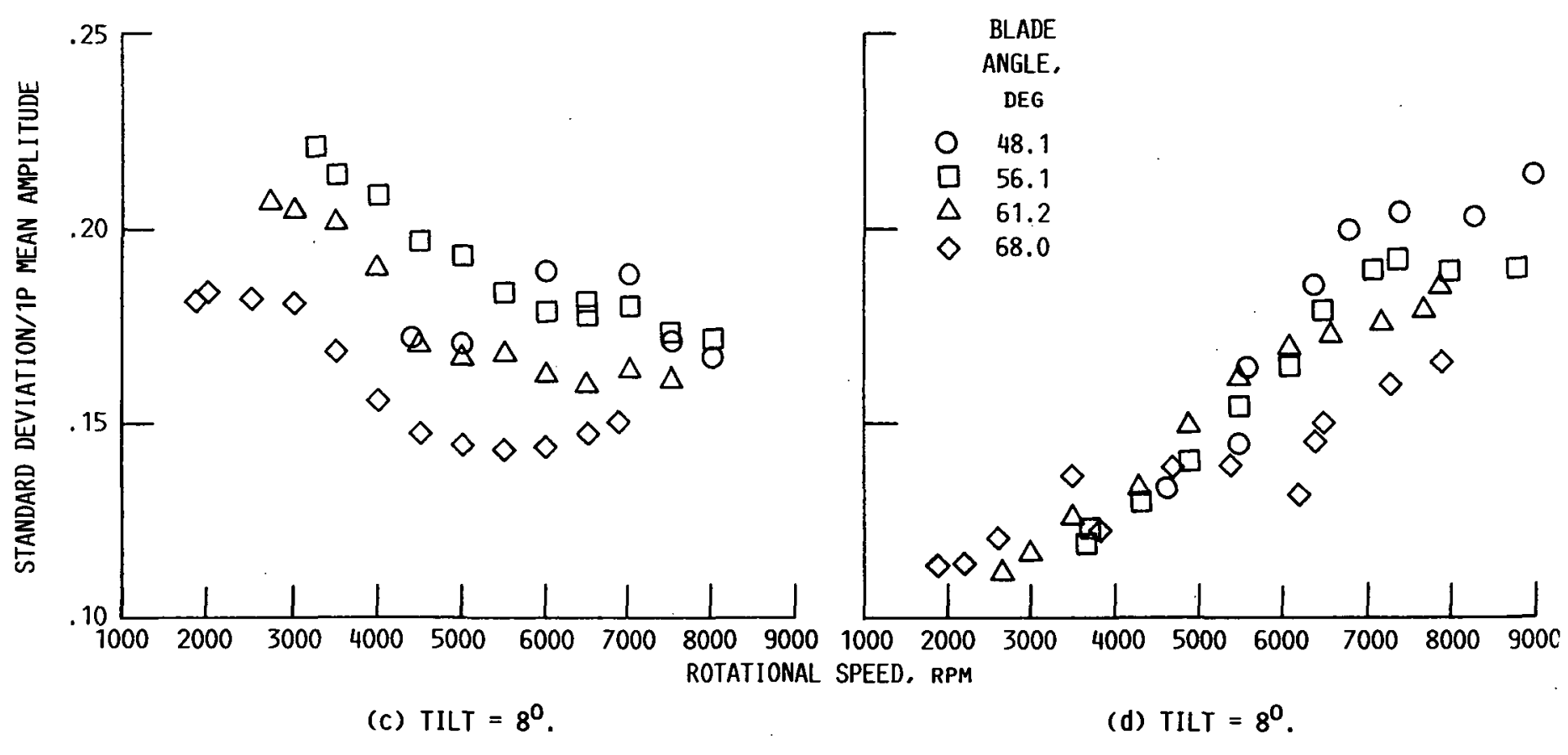

FIGURE 13. - CONTINUED.

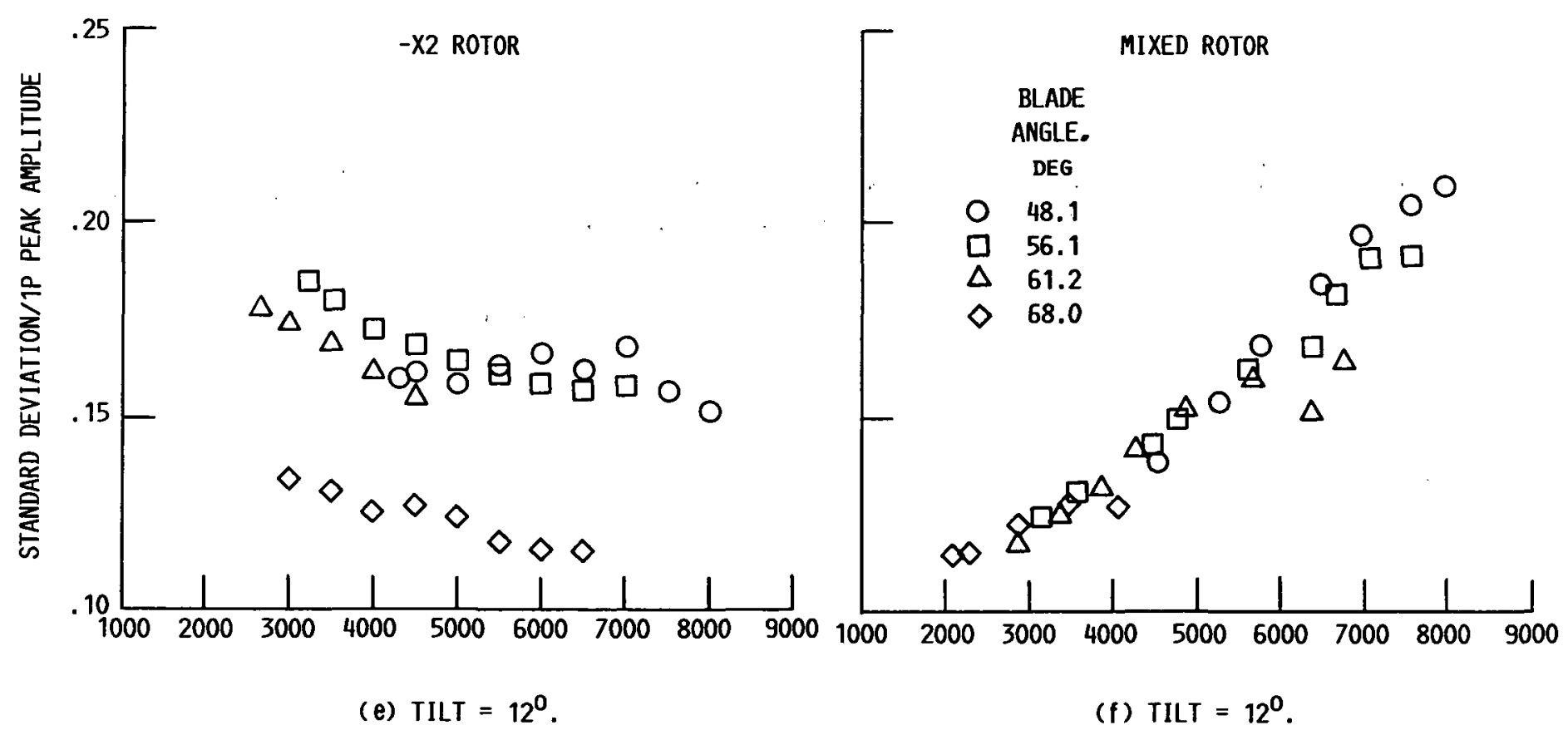

FIGURE 13. - CONCLUDED. 


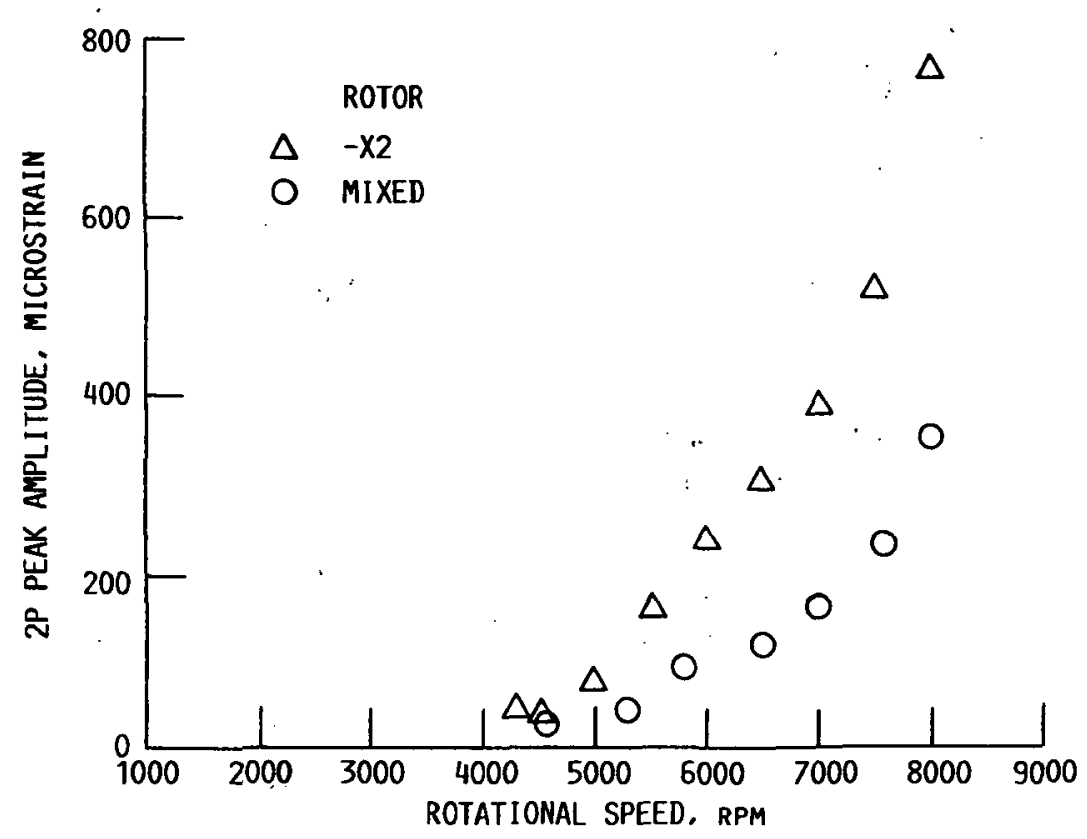

FIGURE 14. - COMPARISON OF 2P PEAK RESPONSE FOR UNIFORM $-X 2$ AND MIXED ROTORS, TILT ANGLE, $8^{\circ}$; BLADE ANGLE, 48. $1^{\circ}$; BLADE 1; STRAIN GAGE 2. 


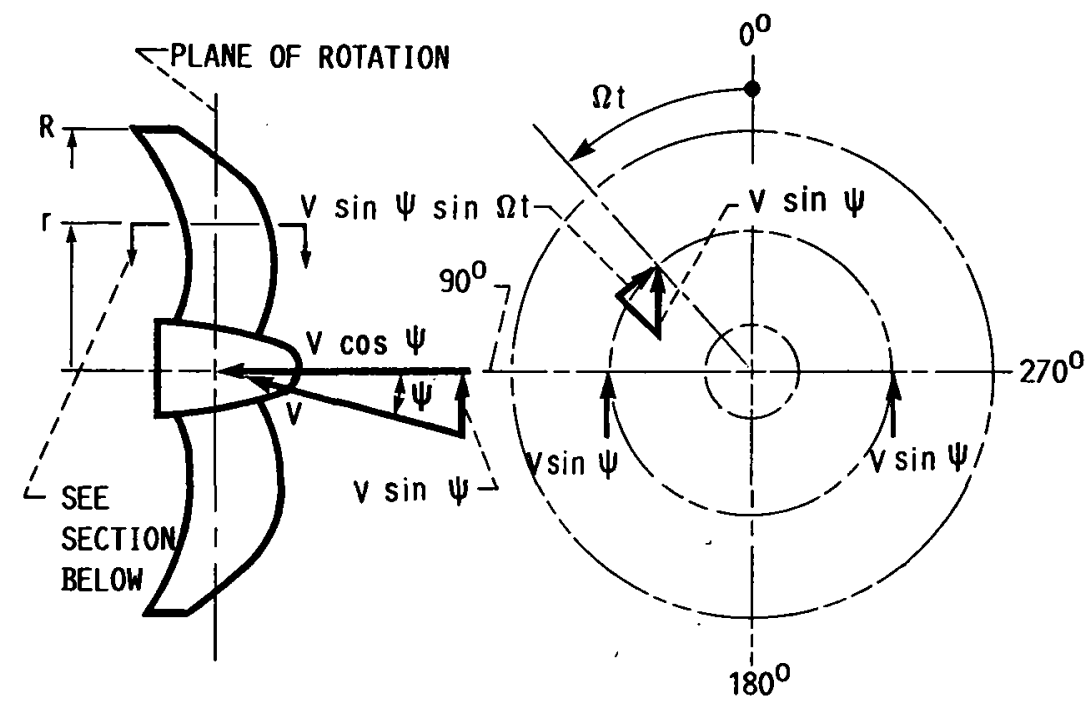

(a) SIDE VIEW

FRONT VIEW

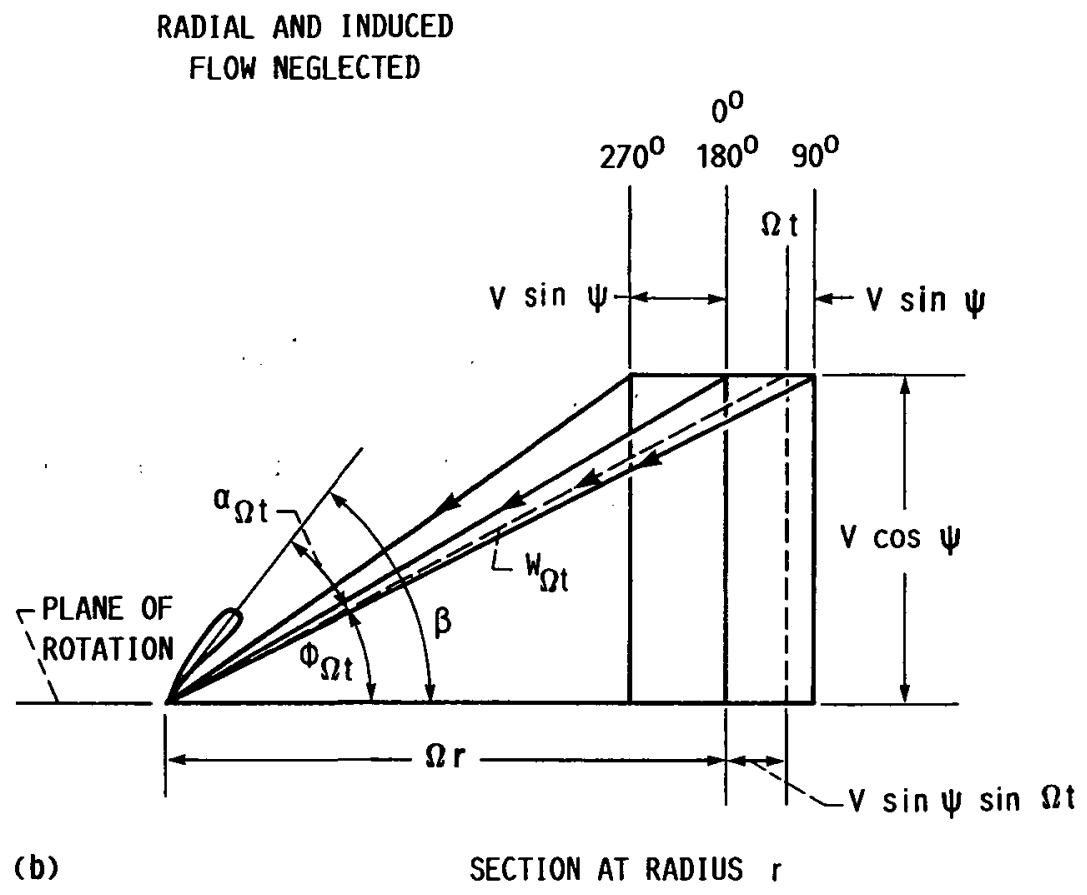

FIGURE B-1. - VELOCITY DIAGRAM FOR A PROPFAN OPERATING IN OFFAXIS FLOW.

CD-88-34945 


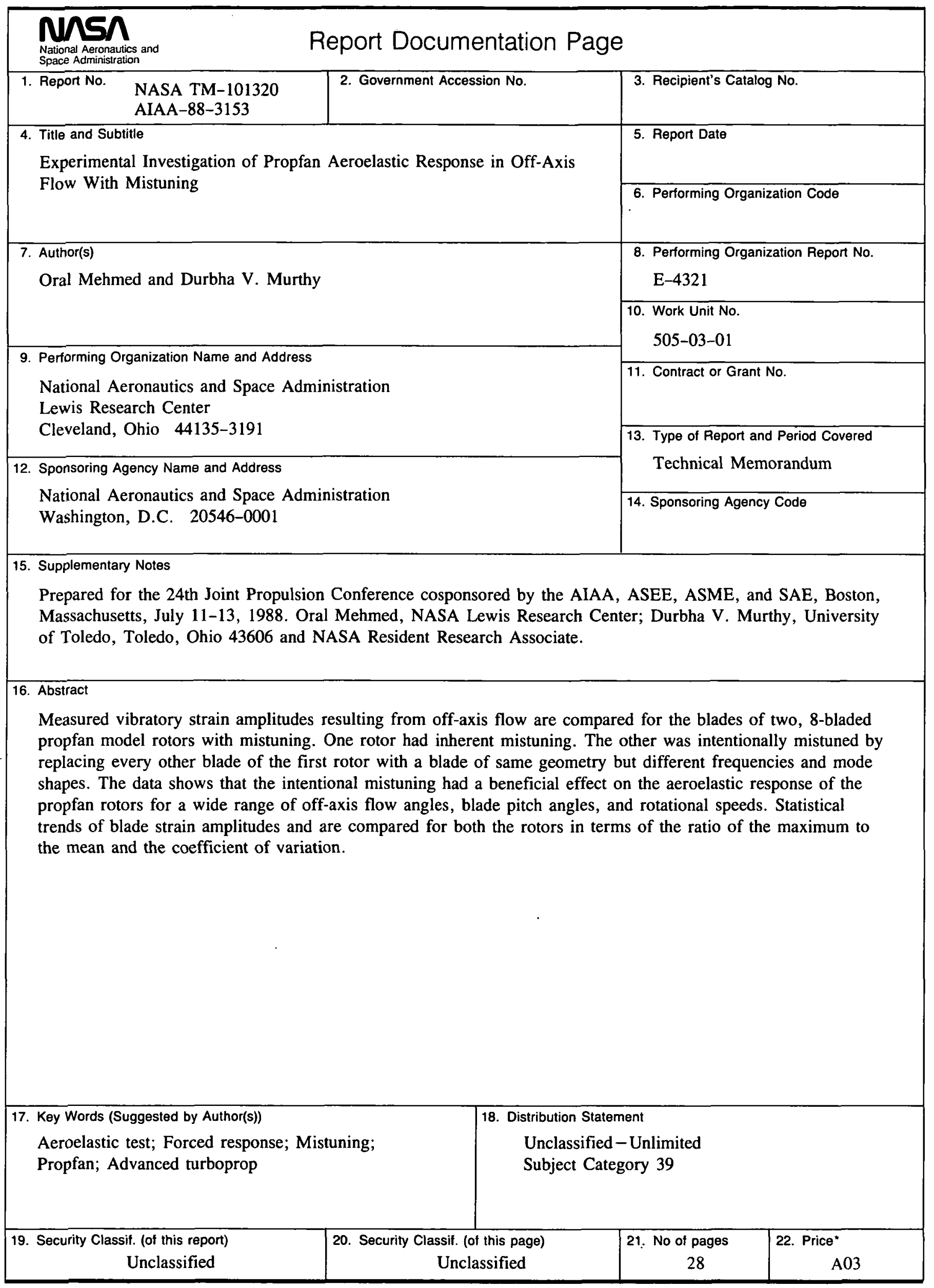


National Aeronautics and

Space Administration

Lewis Research Center

Cleveland, Ohio 44135

Officlal Business

Penalty for Private Use $\mathbf{5 3 0 0}$
FOURTH CLASS MAIL

ADDRESS CORRECTION REQUESTED
|||||

Postage and Fees Paid

Namonal Aeronautics and

Space Administration

NASA 451 